\title{
JOINT VENTURE UM ARCABOUÇO TEÓRICO SOBRE A ESTRATÉGIA ENTRE EMPRESAS
}

\author{
Kelen Renata Knopp Barroca Souza, Edilene Mayumi Murashita Takenaka \\ Universidade do Oeste Paulista - UNOESTE. Curso de Administração, Presidente Prudente, SP. e-mail: \\ kellenrenata15@hotmail.com
}

\section{RESUMO}

A joint venture trata da união de duas ou mais empresas com objetivos em comum formando assim, outra empresa independente com uma equipe diferente para cuidar de seus interesses, podendo associar os capitais dos sócios ou não. O presente trabalho teve por objetivo: apontar os motivos que estão levando muitas empresas a optar pela joint venture, sua importância para as mesmas, e os resultados obtidos. A metodologia utilizada foi o estudo multicasos de empresas que adotaram a joint ventures a partir da analise de documentos, arquivos, e publicações administrativas, também tendo o auxilio de fontes secundarias como pesquisas bibliográficas consultando artigos e livros sobre o histórico do assunto, adotando o método dedutivo para a conclusão do mesmo. Concluímos que a joint ventures pode ser vantajosa para as empresas, diminuindo os riscos, aumentando os lucros, fazendo com que as empresas envolvidas na aliança ganhem mais espaço no mercado.

Palavras-chave: Joint ventures. Empresas. Cooperação entre empresas. Alianças.

\section{JOINT VENTURE: A THEORETICAL SKELETON ABOUT THE STRATEGY BETWEEN BUSINESS}

\begin{abstract}
The joint venture talk about union of two or more business with common goals forming another independent business with a different team for take care about your own concern, that may partner member's capital or not. The present work had as goal: analyse the reasons that are influencing many business to choose joint venture, your importance for them, and the obtained results. the methodology used was the multicases study of business that adopt join ventures from analysis of documents, files, and administrative publications, and also having secondary sources as bibliographic researches consulting articles and books about the history of the subject, adopting the deductive method for the conclusion of joint venture project. We conclude that joint ventures can be advantageous for business, decreasing risks, increasing profits, making business involved in the alliance earn more space on market.
\end{abstract}

Keywords: Joint ventures. Business. Business cooperation. Alliances. 


\section{INTRODUÇÃO}

Joint venture é uma expressão de origem inglesa que significa a união de duas ou mais empresas já existentes que formam uma aliança entre si com o objetivo de realizar atividades econômicas em comum. Tais atividades são acordadas por um período pré-determinado visando a lucratividade desse empreendimento conjunto.

Frente a projetos que envolvam grandes riscos, muitos empresários recorrem a formação de uma joint venture que pode englobar a produção de bens, a prestação de serviços, a procura de novos mercados ou $\mathrm{o}$ apóio mútuo em diferentes níveis da cadeia de um produto, além de aspectos de distribuição e logística.

Porém, mesmo sendo uma opção comumente adotado por grandes empresas, a adoção da joint venture não é de conhecimento de todos, ou seja, é uma estratégia pouco abordada na faculdade, em noticiários e/ou livros. Deste modo, ao optar por esta temática, buscamos aprofundar nosso conhecimento sobre o tema como forma de resposta para algumas dúvidas acerca dos motivos que levam à adoção da joint venture.

Para a realização da presente pesquisa, apontamos os resultados obtidos por seis empresas que optaram por fazer essa aliança: Renault e Nissan; Cosan e Shell;
Ambev e Souza \& Cruz; Perdigão e Unilever; e Grupo Bertin e Atlantia.

Para o desenvolvimento da pesquisa, apresentamos como objetivo geral verificar os motivos que levam as empresas a optar pela joint venture, conhecer a sua importância e eficiência, e verificar os resultados obtidos pelas empresas citadas a partir de suas próprias percepções.

\section{METODOLOGIA UTILIZADA}

O presente estudo pode ser caracterizado como qualitativo, a partir do uso de referencial bibliográfico e de abordagem descritiva. Foi construído através do levantamento de dados encontrados na literatura já existente com a realização de pesquisas bibliográficas por meio de livros, revistas além de pesquisas disponibilizadas no acervo da biblioteca da UNOESTE, em sites específicos sobre o tema e, também, em sites oficiais das empresas analisadas, o que possibilitou coletar diversas informações que contribuíram para o desenvolvimento do presente trabalho de forma esclarecedora.

Faz-se importante ressaltar que, para o presente trabalho, compreender aspectos que envolvem o tema "joint venture" como um mecanismo de cooperação entre em empresas, apresenta-se como primordial. Devido a isso, a utilização do referencial teórico foi suficiente para o objetivo pretendido. A análise de considerações e 
resultados a partir da adoção da joint venture publicadas pelas próprias empresas apontadas reforçam a literatura existente.

As empresas analisadas foram: Renault e Nissan; Cosan e Shell; Ambev e Souza \& Cruz; Perdigão e Unilever; e Grupo Bertin e Atlantia. Tais empresas foram escolhidas devido à facilidade de obtenção de informações sobre as conseqüências da citada aliança e também por representarem diferentes segmentos de mercado.

O presente artigo é resultado de um projeto do Programa Especial e Iniciação Científica cadastrado e aprovado sob o número: Projeto PEIC 1978/2013.

\section{JOINT VENTURES COMO MECANISMO DE COOPERAÇÃO ENTRE EMPRESAS.}

Para Basso (apud SCHOPPE, 2008, p.11) joint ventures são "mecanismos de cooperação entre em empresas, [...] possuem natureza associativa (partilha dos meios e dos riscos) podendo apresentar objetivo e duração limitados ou ilimitados". A partir disto podemos verificar que esta citação menciona que a joint venture é uma partilha ou divisão de riscos, e ao falar de "mecanismos", menciona haver uma disposição das partes para elas funcionarem conjuntamente.

De acordo com Ireland, Hltt, e Hoskisson (2008, p. 247):
Uma joint venture é uma aliança estratégica em que duas ou mais empresas criam uma empresa juridicamente independente para dividir alguns de seus recursos e capacitações, a fim de desenvolver uma vantagem competitiva. As joint ventures são eficazes no estabelecimento de relações de longo prazo e na transferência de conhecimento tácito.

A joint venture tem grande eficácia em relações de longo prazo em que há o compartilhamento de conhecimento tácito, ou seja, o conhecimento que os integrantes da equipe adquiriram ao longo da vida através de suas experiências. Assim, podemos dizer que a adoção de uma joint venture como estratégia vai além da divisão de riscos, existindo compartilhamento financeiro e racional (conhecimento), sempre visando à diminuição de seus riscos e o aumento de suas vantagens perante o mercado.

Já para Barney e Hesterly (2011, p. 268): “Criar uma entidade legal separada, na qual os parceiros de uma aliança investem e da qual os lucros que auferem são retornos sobre seu investimento, reduz parte dos riscos de trapaça de uma aliança estratégica." Enfatizam, os autores anteriormente citados, que a joint venture também é um modo de reduzir os riscos de trapaças por 
algumas das partes aliadas uma vez que, ao trapacear, o empresário fraudador estará prejudicando a(s) empresa(s) aliada(s) e também a sua prórpia empresa, podendo ter a diminuição de lucros sobre seu investimento como consequencia de seus atos ardilosos.

Segundo Ireland, HItt, e Hoskisson (2008, p. 247) "Normalmente, os sócios de uma joint venture têm a mesma participação acionaria e contribuem igualmente para suas operações". A citação relata que, na maioria das vezes, ao se aplicar o capital para o projeto de joint venture, os sócios injetam a mesma proporção financeira, ou seja, se for duas empresas, cada sócio aplicará $50 \%$ do capital total, totalizando assim o $100 \%$ necessário para o projeto.

Entretanto, ainda segundo Ireland, Hltt, e Hoskisson (2008), podem ocorrer casos de participações acionárias diversificadas e, quando isso ocorre, a divisão do lucro é feita proporcionalmente ao seu capital investido, geralmente tendo um lucro maior a empresa que investiu o maior montante.

Assim, podemos dizer que a joint venture possibilita uma divisão de riscos e uma união de esforços, e que para esta aliança dar certo é necessário haver disposição das partes para o funcionamento da mesma.
Lima e Carvalho (2008), apontam as vantagens da adoção de uma joint venture que podem ser resumidas da seguinte forma:

- obter recursos financeiros através da obtenção de um parceiro;

- unificar sinergias e experiências anteriores;

- proporcionar maior controle sobre as operações;

- proporcionar a combinação de capital e riscos, habilidades e recursos, tecnologia e ampliar a presença de mercado com economia de escala em recursos e processo de fabricação;

- combinar diferentes pontos fortes da cadeia de valor

- possibilitar que empresas que não dispõem de recursos de capital suficientes possam procurar sócios para financiar um projeto em conjunto.

Portanto, ao adotar essa forma de cooperação empresarial, faz-se necessário que todos os empresários envolvidos nesse processo tenham compromisso e responsabilidade. É indispensável à cooperação dos sócios ao se tratar de atingir os objetivos e metas a serem alcançados, ou seja, é necessário que ambas as empresas e seus sócios cooperem afins de que a joint venture atinja o sucesso.

\section{RESULTADOS}


Ao fazer o estudo de multicasos, optamos em estudar cinco casos de joint ventures como cooperação empresarial adotada entre empresas. São elas: Renault e
Nissan; Cosan e Shell; Ambev e Souza \& Cruz; Perdigão e Unilever; e Grupo Bertin e Atlantia. Segue uma tabela com os resultados obtidos na pesquisa.

Tabela 1. Pontos positivos e negativos resultantes da adoção da joint ventures - estudo multicaso

\begin{tabular}{|c|c|c|}
\hline $\begin{array}{l}\text { Empresas } \\
\text { Estudadas }\end{array}$ & Pontos positivos às empresas envolvidas & $\begin{array}{c}\text { Pontos negativos às empresas } \\
\text { envolvidas }\end{array}$ \\
\hline $\begin{array}{l}\text { Renault e } \\
\text { Nissan }\end{array}$ & $\begin{array}{l}\text { - Desde sua criação, a Nissan obteve uma } \\
\text { notável recuperação financeira. } \\
\text { - Já a Renault reforçou as suas bases em } \\
\text { termos de desempenho operacional e } \\
\text { acelerou o seu desenvolvimento } \\
\text { internacional. }\end{array}$ & $\begin{array}{l}\text { - Não se encontrou } \\
\text { pontos negativos nos } \\
\text { estudos. }\end{array}$ \\
\hline $\begin{array}{l}\text { Cosan } \\
\text { Shell }\end{array}$ & $\begin{array}{l}\text { - A empresa criada pela joint venture a } \\
\text { Raízen está entre as cinco maiores } \\
\text { companhias do Brasil }\end{array}$ & $\begin{array}{l}\text { - Não se encontrou } \\
\text { pontos negativos nos } \\
\text { estudos. }\end{array}$ \\
\hline $\begin{array}{l}\text { Ambev e } \\
\text { Souza \& } \\
\text { Cruz }\end{array}$ & $\begin{array}{l}\text { - A Agrega empresa gerada pela joint } \\
\text { venture esta cumprindo com eficiência o } \\
\text { abastecimento do setor de suprimentos } \\
\text { de seus clientes. }\end{array}$ & $\begin{array}{l}\text { - Não se encontrou } \\
\text { pontos negativos nos } \\
\text { estudos. }\end{array}$ \\
\hline $\begin{array}{l}\text { Grupo } \\
\text { Bertin e } \\
\text { Atlantia }\end{array}$ & $\begin{array}{l}\text { - A empresa gerada a: AB Concessões está } \\
\text { atuando nas rodovias com } \\
\text { aproximadamente } 1.000 \text { quilômetros de } \\
\text { estradas. }\end{array}$ & $\begin{array}{l}\text { - Não ter atingido um dos } \\
\text { objetivos que era atuar } \\
\text { no setor de aeroportos }\end{array}$ \\
\hline $\begin{array}{l}\text { Perdigão } \\
\text { e Unilever }\end{array}$ & $\begin{array}{l}\text { - A Becel passou a ser mais desenvolvida. } \\
\text { - A Perdigão ampliou o seu segmento de } \\
\text { margarinas. }\end{array}$ & $\begin{array}{l}\text { - Não se encontrou } \\
\text { pontos negativos nos } \\
\text { estudos. }\end{array}$ \\
\hline
\end{tabular}

Fonte: Pesquisa realizada junto a sites oficiais das empresas pesquisadas. Elaborada pela autora.

\section{DISCUSSÃO}

Ao analisar os resultados da joint ventures entre uma empresa Francesa - a Renault, e uma Japonesa - a Nissan, observamos que a Nissan teve uma recuperação financeira e a Renault reforçou suas bases operacionais, acelerando o seu desenvolvimento internacional.
A aliança feita entre duas empresas brasileiras, a Cosan e a Shell, propiciou à Raízen (empresa criada através da joint ventures) estar entre as cinco maiores companhias do Brasil e que tem se expandido bastante, ou seja, através de joint ventures as empresas conseguiram atingir seus objetivos. 
O terceiro caso também se trata de duas empresas brasileiras que são a Ambev e a Souza \& Cruz e o resultado foi que a Agrega (empresa gerada pela joint venture) cumpriu com eficiência o abastecimento do setor de suprimentos de seus clientes a partir de melhorias no processo de aquisição de materiais.

O quarto caso trata de uma grande construtora Italiana, a Atlantia, e um grande grupo de empresas Brasileiras, o Grupo Bertin, cujo objetivo era focar no segmento de transporte e ganhar as concessões dos aeroportos. Verificamos que, apesar de não conseguirem as concessões, a empresa gerada pela joint venture concluiu quatro projetos no segmento de transportes.

Por fim, o caso da Unlever, uma empresa Inglesa e a Perdigão, uma empresa Brasileira, que adotaram a joint venture com o objetivo de destacar a marca Becel e agregar a cartilha de produtos da Perdigão juntamente com um produto no segmento de margarina. A partir da adoção da joint venture, a Becel passou a ser mais desenvolvida, e a Perdigão ampliou o seu segmento de margarinas.

Comparando a relação de vantagens apontadas pelos autores da presente pesquisa para a adoção da joint venture e os resultados obtidos pelas empresas escolhidas para o estudo multicaso, podemos observar a ocorrência de itens em comum envolvendo ampliação de mercado e de ganhos de capital.

\section{CONSIDERACÕES FINAIS}

A temática "Joint Ventures" trata de um assunto muito interessante e importante para o conhecimento de todos, principalmente para empresários, administradores e gestores.

A realização da presente pesquisa propiciou um melhor entendimento sobre os aspectos que envolvem o tema "joint venture" como uma parceria entre empresas com competências diversas que formam uma aliança com o intuito de unir forças e criar uma sinergia para o alcance de objetivos em comum que envolvem o aumento da lucratividade a partir da ampliação dos negócios das empresas abarcadas.

Após 0 estudo multicaso, consideramos que, em relação aos casos analisados, foi possível verificar que a joint venture, como uma aliança estratégica pode ser muito vantajosa e agrega muito valor para as empresas, além de diminuir risco de perdas e falências. 


\section{REFERENCIAS}

Ambev. Histórico. Disponível em: <http://www.ambev.com.br/a-

ambev/historico> Acesso em 13 de maio de 2014.

Atlantia. História do grupo. Disponível em: $<$ http://translate.googleusercontent.com/tr anslate $c$ depth $=1 \& \mathrm{hl}=\mathrm{pt}-$

BR\&prev=/search\%3Fq\%3DATLANTIA\%26bi w\%3D1511\%26bih\%3D741\&rurl=translate.g oogle.com.br\&sl=it\&u=http://www.atlantia. it/it/il-

gruppo/storia.html\&usg=ALkJrhgymZ2|Enw COZ3YJWZLBJr 3KpWgQ> Acesso em 13 de maio de 2014.

BARNEY, J. B.; HESTERLY, W. S. Administração estratégica e vantagem competitiva. 3 Ed. São Paulo: Pearson, 2011.

Becel. Unilever. Disponível em: <http://www.unilever.com.br/Images/Becel tcm95-107541.pdf > Acesso em 13 de maio de 2014.

BERTIN GRUPO. Quem somos. Disponível em: <http://www.grupobertin.com.br/> Acesso em 13 de maio de 2014.

COSAN/RAIZEN. Disponível em: <http://www.cosan.com.br/Raizen> Acesso em 13 de maio de 2014.

COSAN. Trajetória. Disponível em:<http://www.cosan.com.br/Cosan/Traje toria $>$ Acesso em 13 de Maio de 2014

FUSÕES e aquisições. Italiana Atlantia se une a Bertin em rodovias. Disponível em:<http://fusoesaquisicoes.blogspot.com. br/2012/01/italiana-atlantia-se-une-bertinem.html> Acesso em 13 de maio de 2014.

HITT, M. A.; HOSKISSON, R. E. ; IRELAND, R. D. Administração estratégica. 2 Ed. São Paulo: Thomson, 2008.

LIMA, G. B. ; CARVALHO, D. T. Joint Venture como estratégia de internacionalização de empresas: um ensaio teórico. Disponível em: $<$

http://www.convibra.com.br/2008/artigos/9 $\underline{6}$ 0.pdf $>$ Acesso em 13 de maio de 2014.

NISSAN. Nissan no Brasil. Disponível em: $<$ http://www.nissan.com.br/\#nissanbrasil\%2Fhistorico-nissan> Acesso em 07 de Maio de 2014.

PERDIGÃO: viver da uma fome. História e tradição. Disponível em: <http://www.perdigao.com.br/institucional $>$ Acesso em 13 de maio de 2014.

PIZA, J. M. T. Fusões e aquisições: Um estudo de caso de dois processos envolvendo empresas de Catering aéreo. São Carlos, 2010. Disponível em: < http://www.bmaiscompet.com.br/arquivos/5 USP Cases-de-MeA.pdf> Acesso em 19 de Maio de 2014.

RAIZEN. Quem somos. Disponível em: <http://www.raizen.com/pt-br/a-

raizen/quem-somos> Acesso em 13 de maio de 2014.

RENAULT Brasil. Historia do grupo Renault. Disponível em: <http://www.renault.com.br/mais renault/ historia do grupo renault/> Acesso em 07 de Maio de 2014.

SCHOPPE, J. H. Fatores de sucesso para implementação de joint ventures teuto Brasileiras no Brasil. Santa Catarina, 2008. Disponível em < http://tcc.bu.ufsc.br/Adm291033>. Acesso em 24 de Setembro de 2013.

SHELL Brasil. Década de 1910 a 2010. Disponível em: $<$ http://www.shell.com/bra/aboutshell/cen tenary/first-100-years/1910.html> Acesso em 13 de maio de 2014.

SOUZA CRUZ.. Nossa história. Disponível em: $<$ http://www.souzacruz.com.br/group/sites 
/SOU 7UVF24.nsf/vwPagesWebLive/DO7V9 K2W?opendocument\&SKN=1 > Acesso em 13 de maio de 2014.

UNILEVER. História da Unilever no Brasil. Disponível em: <http://www.unilever.com.br/aboutus/unil ever no brasil/> Acesso em 13 de maio de 2014.

VILAELA, A. L. B. A formação de joint ventures como alternativa para investimentos estrangeiros no setor sucroalcooleiro brasileiro. Franca, 2008.
Disponível em: $<$ http://www.dominiopublico.gov.br/downlo ad/teste/arqs/cp064329.pdf> Acesso em 26 de Outubro de 2013.

Recebido para publicação em 04/07/2014 Revisado em 05/08/2014

Aceito em 22/08/2014 